Open Access

Mario Bisiada*

\title{
Structural effects of English-German language contact in translation on concessive constructions in business articles
}

DOI 10.1515/text-2016-0007

\begin{abstract}
Studies on a variety of languages have observed a shift away from hypotactic, hierarchical structures towards paratactic, incremental structures, and have attributed this to language contact with English in translation. This paper investigates such a shift towards parataxis as the preferred structure of concessive constructions in German business articles. To this effect, a diachronic corpus method that has been applied to popular science articles in existing studies is adopted and applied to business articles, in an attempt to reproduce existing findings for this genre. This method is complemented by a corpus of manuscripts which allow to control for the effect of editing on the translated texts. Based on the analysis of hypotactic and paratactic translations of English concessive conjunctions between 1982/83 and 2008, I argue that hypotactic structures are indeed used less frequently in translated texts, but that this development is restricted to translated language. In non-translated texts, the use of hypotactic conjunctions has increased. The use of sentence-initial conjunctions, however, does seem to spread in this genre (as was reported for popular science), which may be further evidence for it to be a case of language change through contact in translation.
\end{abstract}

Keywords: language contact in translation, translation and language change, corpus-based translation studies, business translation, concessive constructions

\section{Introduction}

This paper aims to contribute to the study of language change through language contact in translation by adopting the diachronic corpus research method from

*Corresponding author: Mario Bisiada, Department of Translation and Language Sciences, Universitat Pompeu Fabra, Barcelona, Spain, E-mail: mario.bisiada@upf.edu

(c) BY-NC-ND ( ) 2016, Mario Bisiada. This work is licensed under the Creative Commons Attribution-NonCommercial-NoDerivatives 3.0 License. 
an existing research project on popular science articles (see House 2011b). Studies in that project found, among other things, a trend towards a replacement of hypotactic concessive structures, which require a verb-final subordinate clause as in example (1b), by paratactic ones, which coordinate two verb-second main clauses, as in example (1a) (Becher 2011).

(1) Although strategy had considerable breadth then, it didn't have much rigor. (HBR 1/08,54)

a. Das Thema Strategie hatte damals zwar eine gewisse Bandbreite, doch es mangelte an Disziplin. (manuscript 4)

b. Obwohl das Thema Strategie damals umfangreich behandelt wurde, mangelte es ihm an Stringenz. (HBM 5/08,10)

They also found an increasing use of sentence-initial concessive conjunctions such as aber and doch (Becher et al. 2009). Using their diachronic corpus method, I investigate in the present paper whether their findings can be reproduced in the genre of business articles. The aim is to increase the range of analysed genres in order to enable us to make more generalizable statements about trends in German translated and non-translated language, and learn more about the possibilities and limitations of diachronic corpus studies of language contact in translation.

The article also seeks to promote the inclusion of translation manuscripts into corpora, which allows researchers to study the effects of editorial intervention in the translation process as a whole. A case of such editorial intervention is exemplified in (1) above, where the editor replaced a paratactic structure by a hypotactic one. As I will argue, the differentiation of language that is the outcome of the translation act from language that was influenced by agents other than the translator allows researchers to verify that the results in question really relate to translated language. Such a differentiation may also provide interesting insights into what happens to a multilingually created document during the many steps of its production.

The paper is structured as follows. In Section 2, I review some relevant literature in the subfield of translation and language change. Section 3 describes the corpus structure and size, followed by an outline of the method that has been adopted and the conjunctions to be analysed. The next sections contain the analyses of hypotaxis and parataxis (Section 4) and of sentence-initial concessive conjunctions (Section 5). Finally, I discuss the implications of this study for the alleged developments in, firstly, taxis in German, and secondly, sentenceinitial concessive conjunctions as markers of concessive relations in this genre (Section 6). 


\section{Structural effects of language contact in translation}

A growing academic interest has focussed on the corpus-based study of language contact in translation and the effect of the source language on the target language, especially regarding English as the source language (see, for instance, Baumgarten 2007, Baumgarten 2008; Fischer 2007; House 2011a, House 2011b; Kranich 2011; Kranich et al. 2012; Malamatidou 2013). As far as structural effects of English-German language contact in translation are concerned, it has been established that these are more likely found in frequency shifts of existing structures than in syntactic innovations (Kranich et al. 2011: 37; Kranich 2014: 112). In spite of this, an important caveat is that it cannot be proved beyond doubt that observed changes in translation corpora have been affected by language contact in language users' exposure to translations or to English articles directly (Neumann 2011: 242-243).

Studies of language contact in translation usually adopt the view that structures or patterns that are conventionally used less often in the target language exhibit an increase in usage frequency (Koller 1998). They may eventually even compete with other patterns that exist for this particular communicative function (Baumgarten and Özçetin 2008).

Some of those studies have reported a cross-linguistic increase in popularity of coordinated, paratactic structures, at times at the expense of hypotaxis, and attributed this shift to the status of English as a lingua franca (Musacchio 2005; Becher 2011; Bennett 2011, Bennett 2013; Hansen-Schirra 2011; Bisiada 2013). However, despite the absence of structurally marked subordination, English can often be shown to exhibit a more hierarchical and subordinated structure characteristic of a hypotactic style than German does (Fischer 2007: 397, Fischer 2013; Bisiada 2014).

In an analysis of translations of the concessive conjunction although in popular science articles, Becher (2011: 195) observes that 19\% of them were hypotactic in 1999-2002, as opposed to 55\% in 1978-1982, while paratactic translations increased in proportional frequency from $27 \%$ to $59 \%$ over the same time span. The comparable non-translated texts are also reported to show an increase in parataxis, from 48.5 instances per 10,000 words in 1978-1982 to 70 in 1999-2002, while hypotaxis does not increase (Becher 2011: 197).

In his interpretation of the results, Becher (2011: 197) argues that, in popular science, hypotaxis is already a "Randerscheinung” ('marginal phenomenon') in non-translated language, with parataxis being the preferred construction type. 
He argues that the frequency of hypotaxis in the translations may have assimilated to its frequency in the non-translations through the translators' conservative language use (Becher 2011: 198).

In another study using the same corpus of popular science articles, Becher et al. (2009) investigate the translation of the English sentence-initial concessive conjunction but into German. They find a lower frequency of sentence-initial aber and doch (both mean 'but') compared to but (Becher et al. 2009: 143), arguing that German has "a stricter organization of the sentence in terms of given and new information than English," so that "German prefers to use a sentence-internal connective in many situations where English would use a sentence-initial one" (Becher et al. 2009: 137). As a second explanation, they draw on research conducted by House (2006), among others, to argue that sentence-initial concessive conjunctions are more common in English discourse, which they consider more "interactional, dialogous and addressee-oriented" while German discourse is described as "transactional, monologous and content-oriented” (Becher et al. 2009: 138).

Their data show that, over the analysed time span, translations of but into German using sentence-initial aber and doch have almost doubled, while the number of "free" translations has decreased by an equivalent amount (Becher et al. 2009: 144). The non-translations also show a strong increase in frequency of sentence-initial aber and doch (Becher et al. 2009: 143). They call these conjunctions sentence-initial "show concessions," used to achieve an "interactional" style, and explain their findings as "an adoption of textual norms introduced by the English-German translations” (Becher et al. 2009: 145-146).

\section{Corpora and methodology}

\subsection{The corpus architecture}

This study combines a diachronic parallel corpus with a diachronic comparable corpus of business articles, and also draws on a manuscript corpus, all of which I have compiled:

- Parallel corpus: English originals and their published German translations

- Comparable corpus: German non-translations

- Manuscript corpus: a parallel corpus as above as well as unedited manuscripts of the translations 
The business genre was chosen because it combines journalistic and scientific aspects so that the discourse is produced under similar constraints to popular science articles. The sources for the corpora are the Harvard Business Review, an American business magazine, and its German edition, the Harvard Business Manager. In the compilation of the parallel corpus, the translations were sentence-aligned with the source text sentences. For the manuscript corpus, there is a three-way alignment of source text, manuscript target text and published target text. The parallel corpus and comparable corpus are divided into two subcorpora, one containing texts from 1982 to 1983 and the other containing texts from 2008. The time span of 25 years that separate the two sample periods allows a reliable replication of previous research, which has drawn on a corpus whose two sample periods were separated by about 20 years (Becher et al. 2009: 126; Becher 2011: 191).

The sizes of the parallel and comparable corpora are shown in Table 1. All issues of the German publication consist of two-thirds translations and one-third non-translations, which means that the size of the comparable corpus will necessarily be smaller than that of the parallel corpus. However, the comparable corpus is only used to validate the results found in the analysis of the parallel corpus. Therefore, its size is of minor importance and is determined by the time periods that were chosen for this study.

Table 1: Size of the parallel corpus and comparable corpus in words.

\begin{tabular}{llrr}
\hline & & $\mathbf{1 9 8 2 / 8 3}$ & $\mathbf{2 0 0 8}$ \\
\hline Parallel corpus & English source texts & 251,148 & 258,589 \\
& German translations & 246,341 & 260,261 \\
Comparable corpus & German non-translations & 145,715 & 88,312 \\
Total size & & 643,204 & 607,162 \\
\hline
\end{tabular}

The authors of the articles in the corpus are one-off contributors, so the analysis draws on more than 100 different language users. The translations were done by professional freelance translators, small translation businesses, as well as editorial staff. The articles in the 1982/83 subcorpus have been translated by nine different translators, while the articles in the 2008 subcorpus have been translated by sixteen individual translators as well as a translation company.

The texts in the manuscript corpus originate from 2006 to 2011 (see Table 2). They were translated by the translation agency Rheinschrift and submitted to the publisher of the magazine, where they were then edited. This corpus thus contains different versions of the same translated texts, before and after editing. 
Table 2: Size of the manuscript corpus in words.

\begin{tabular}{lr}
\hline & 2006-2011 \\
\hline English source texts & 104,678 \\
German translations (before editing) & 106,829 \\
Published German translations & 104,448 \\
Total size & 315,955 \\
\hline
\end{tabular}

\subsection{Extending the diachronic corpus method}

This diachronic corpus study uses a two-step method. In the first step, German translations of the English articles from 1982/83 are compared with those from 2008 to determine diachronic changes in, firstly, the translation of the concessive conjunctions although, (even) though, while and secondly, sentence-initial but. The second step of the analysis investigates the comparable corpus to find out whether the changes observed in the translations also happened in the nontranslated articles. To that end, the German conjunctions that have been identified in the parallel corpus are analysed in the comparable corpus to see whether any patterns are developments exclusive to translated text or whether they are taking place in the language as a whole within this genre.

In addition, an analysis of the manuscript corpus will show whether any patterns observed in the parallel and comparable corpora are really the product of the translation stage or whether they are also affected by the editing stage. The multitude of different phases through which a multilingually produced text goes in the process of publication (see e. g. Mossop 2014) warrants a differentiated analysis of the entire process of document production, which will bring about "improvements in the ecological validity of experimental settings” (Muñoz Martín 2010: 179).

Therefore, the manuscript corpus analysis aims to corroborate the existence of patterns in translation manuscripts to ensure that any observations can really be attributed to the language of translation. If the patterns are instead introduced only at the editing stage, that might be evidence to suggest that the phenomenon must, at least in part, be attributed to editors rather than translators (for an application of this method to sentence splitting, see Bisiada 2014). In that case, the driving forces of a particular phenomenon may not lie entirely within translation as multilingual discourse, but also be partly exerted by normative linguistic policies applied within a more monolingual framework. ${ }^{1}$

1 Though editing is certainly no monolingual activity (the editors of the Harvard Business Manager say they always consult the source texts), the constraints it applies to the text are monolingual, based on readability concerns and house styles. 


\subsection{The concessive connectives under analysis}

The English concessive conjunctions whose translations are analysed in this study are although, though, ${ }^{2}$ even though and while, as well as but where it occurs sentence-initially. Following König et al. (1990: 25-29), the equivalent German constructions can be hypotactic, in which case the connective grammatically marks the subordination of one clause to the other by selecting a verb-final word order for the clauses they govern. Alternatively, they can be paratactic, which means that the conjunction coordinates two clauses, each of which has a verbsecond word order. Paratactic connectives can be conjunctions or conjunctive adverbs, as exemplified in (2).

(2) Although education and training won't hurt, and may even help, their effect on the supply of leaders is negligible. (HBR $2 / 77,89)^{3}$

a. Erziehung und Ausbildung können zwar nicht schaden und sogar ganz nützlich sein, aber ihre Wirkung auf das Angebot von Führern ist unbedeutend. (HBM 2/82,72)

b. Erziehung und Ausbildung können zwar nicht schaden und sogar ganz nützlich sein, ihre Wirkung auf das Angebot von Führern ist aber unbedeutend.

Example (2a) shows aber used as a conjunction. The conjunction connects the two clauses, but is not part of either of them. The example also shows the use of the particle zwar (roughly 'it is true that'), which is commonly added to express the tight relationship between the clauses.

Example (2b) has been slightly rearranged so that aber is now used as a conjunctive adverb. Like a conjunction, a conjunctive adverb connects two clauses semantically, but acts as part of the verb phrase and is thus part of the syntactic structure instead of being outside of it (Hentschel 2010: 157).

The remaining translation possibilities will be classed as non-tactic clause connections. They include cases where there is an asyndetic coordination (see e. g. Fitzgerald 2014) or where the concessive clause has been omitted or turned into a prepositional phrase (using, for instance, trotz 'despite').

In addition to the conjunctions reflecting a conjunction in the source text, I have also looked at conjunctions that were introduced by translators in

2 Except where it introduces a verbless concessive clause or serves as a discourse marker rather than a conjunction (see Barth-Weingarten and Couper-Kuhlen 2002: 353).

3 The code assigned to the texts in the corpus is read, for the present example, as Harvard Business Review, number 2/1977, article beginning on page 89. 
environments where the source text does not have an equivalent hypotactic or paratactic conjunction. The insertion of connectives is seen as a form of risktaking on the part of the translator (Musacchio and Palumbo 2010: 9). This type of analysis is necessarily speculative because there is no way of knowing whether the translator consciously decided to supply a hypotactic or paratactic construction.

I thus discuss only conjunctions that were introduced with a frequency of more than one instance per hundred thousand words at one of the time periods under analysis. Introduced instances of aber and wenn auch are not included, as they can be used in a wide range of functions other than the conjunctive one, so that the degree of speculation in this analysis would be increased beyond an acceptable extent.

\subsection{Frequency units and the relative frequency ratio}

The data in this paper are presented using three values: the absolute frequency $(n)$, the normalized frequency $(f$, given in instances per hundred thousand words) and the proportional frequency, which is the percentage with which a construction occurs within its group of related constructions.

A range of frequency counts is necessary to adequately observe trends between the parallel corpus and the comparable corpus. As outlined above, the analysis of the parallel corpus focuses on the conjunctions that are translations of four English conjunctions. In the comparable corpus, where there is no source text, every instance of an item is counted, which complicates the analysis of multifunctional items, such as aber. Thus, the normalized frequencies will be different when comparing one corpus with the other. Proportional frequencies are not subject to this problem, but to ensure comparability between the corpora, it is desirable to draw on both values at all times.

To be able to compare trends between the corpora, it may suffice to focus on the difference between the normalized frequencies instead of the frequencies themselves. Because the frequencies are consistent within each corpus, we can describe the diachronic difference between the corpora by correlating the corresponding data from each of the two sample points (1982/83 and 2008).

To do this, I propose to use the relative frequency ratio as a measurement of diachronic difference between two sample points in a corpus. The relative frequency ratio is usually applied in corpus studies to compare word frequencies between subject-specific and general texts (Edmundson and Wyllys 1961: 227) and has been described as being "mainly useful to find subject-specific collocations” (Manning and Schütze 1999: 176). 
The prime example of this method is the corpus study by Damerau (1993: 435) who argues that the relative frequency of a term will be higher in a domain corpus than in a general corpus, and uses the relative frequency ratio to extract key words from the subject-specific corpora. In terms of the comparison of two corpora, Damerau (1993: 444-445) found that "a simple ratio of subject matter relative frequency to total sample relative frequency is about as good as more elaborate calculations, and in some instances superior." A diachronic corpus analysis at two points in time is basically a comparison of the frequency of the features under analysis at the later stage with the frequency of that same feature at the earlier stage. Thus, the relative frequency ratio can be applied to show diachronic developments between corpora in such settings.

The relative frequency ( $r$ ) of an item ( $i$ ) is calculated by dividing the absolute frequency by the corpus size. The relative frequency of an item in the 2008 parallel corpus is then set in relation to that of the same item in the 1982/83 corpus so that the computed value will reflect potential diachronic changes. The higher the numerator (the relative frequency of a given construction in the 2008 corpus) in relation to the denominator (the relative frequency of a given construction in the 1982/83 corpus), the higher the value. The formula to calculate the relative frequency ratio is below.

$$
R_{i}=\frac{r_{i 2008}}{r_{i 1982 / 3}}=\frac{\frac{n_{i 2008}}{N_{2008}}}{\frac{n_{i 1982 / 3}}{N_{1982 / 3}}}
$$

Thus, a high value means that there is a diachronic increase in relative frequency as well as in normalized frequency because the latter is basically the relative frequency multiplied by, for instance, 100,000. Due to the exponential nature of the graph representing the equation of $R$, I consider a value as indicating a decline if it is below 0.5. In order to indicate an increase in frequency, it must be above 2. A value of 1 means that the frequencies in both corpora are exactly the same, so the closer a value is to 1 , the less change there is in the frequency.

\section{Hypotaxis and parataxis in concessive constructions}

\subsection{Analysis of the parallel corpus}

The conjunctions that were used to translate although, (even) though and while are shown in Table 3. There is an overall decrease in concessive conjunctions in 
Table 3: German translations of English concessive conjunctions: normalized frequencies $(f)$.

\begin{tabular}{|c|c|c|c|c|}
\hline & & & $1982 / 83$ & 2008 \\
\hline \multirow[t]{8}{*}{ Hypotaxis } & & obwohl & 19.5 & 9.1 \\
\hline & & wenn auch & 3.0 & 0.6 \\
\hline & & auch wenn & 2.4 & 3.3 \\
\hline & & selbst wenn & 1.8 & 0.6 \\
\hline & & obgleich & 1.4 & 1.0 \\
\hline & & wenngleich & 0.6 & 0.2 \\
\hline & & obschon & 0.6 & 1.2 \\
\hline & & während & 3.2 & 1.2 \\
\hline \multirow[t]{7}{*}{ Parataxis } & Conjunctive adverb & aber & 6.8 & 3.1 \\
\hline & & jedoch & 1.8 & 2.1 \\
\hline & & doch & 0.4 & 1.5 \\
\hline & & allerdings & 0.4 & 1.0 \\
\hline & & other & 1.0 & 0.6 \\
\hline & Paratactic conjunction & aber & 3.6 & 4.6 \\
\hline & & doch & 0.6 & 4.6 \\
\hline \multirow[t]{2}{*}{ Non-tactic } & & asyndetic & 1.4 & 1.3 \\
\hline & & other & 2.8 & 1.9 \\
\hline Total & & & $51.3(n=255)$ & $36.6(n=190)$ \\
\hline
\end{tabular}

the translations: While in 1982/83, they occurred at a normalized frequency of 51.3, they only occurred at a frequency of 36.6 in 2008. This may mean that concessive conjunctions are becoming rarer in the source texts in this genre.

Obwohl is the most frequently used translation for concessive conjunctions and remains so despite its decline in usage frequency. Regarding the remaining conjunctions, even though there are not many instances in this corpus, it seems that in the 1982/83 corpus, translators maintained a diversity of means to express concessive relationships (wenn auch, selbst wenn, auch wenn), whereas the genre convention now seems to be the intensifier-conjunction combination auch wenn.

The conjunction aber occurs more frequently now than it used to (3.6 in 1982/83 compared to 4.6 in 2008); but as a conjunctive adverb, it occurs less frequently (6.8 down to 3.1). An overall increase is exhibited by doch, which was hardly used at all in 1982/83 and has increased significantly over the analysed time span, especially in its function as a conjunction.

Thus, there is a strong decrease in the frequency of hypotactic conjunctions (Table 4). Their normalized frequency has halved (32.4 to 15.8), and in relative terms they are now only used in $43 \%$ instead of $63 \%$ of cases. Conjunctive 
Table 4: Usage frequencies of conjunctions and adverbs in the parallel corpus.

\begin{tabular}{|c|c|c|c|c|c|c|c|c|c|}
\hline & & \multicolumn{2}{|c|}{$\begin{array}{r}\text { Hypotactic } \\
\text { conjunctions }\end{array}$} & \multicolumn{2}{|c|}{$\begin{array}{r}\text { Conjunctive } \\
\text { adverbs }\end{array}$} & \multicolumn{2}{|c|}{$\begin{array}{r}\text { Paratactic } \\
\text { conjunctions }\end{array}$} & \multicolumn{2}{|r|}{ other } \\
\hline & & $1982 / 83$ & 2008 & $1982 / 83$ & 2008 & $1982 / 83$ & 2008 & $1982 / 83$ & 2008 \\
\hline \multirow[t]{3}{*}{ although } & $n$ & 67 & 37 & 26 & 23 & 11 & 19 & 5 & 10 \\
\hline & $f$ & 13.5 & 7.1 & 5.2 & 4.4 & 2.2 & 3.7 & 1.0 & 1.9 \\
\hline & & $61 \%$ & $42 \%$ & $24 \%$ & $26 \%$ & $11 \%$ & $21 \%$ & $4 \%$ & $11 \%$ \\
\hline \multirow[t]{3}{*}{ though } & $n$ & 28 & 12 & 7 & 8 & 2 & 4 & 6 & 4 \\
\hline & $f$ & 5.6 & 2.3 & 1.4 & 1.5 & 0.4 & 0.8 & 1.2 & 0.8 \\
\hline & & $65 \%$ & $43 \%$ & $16 \%$ & $28 \%$ & $5 \%$ & $15 \%$ & $14 \%$ & $15 \%$ \\
\hline even & $n$ & 41 & 19 & 0 & 2 & 0 & 3 & 2 & 0 \\
\hline \multirow[t]{2}{*}{ though } & $f$ & 8.2 & 3.7 & - & 0.4 & - & 0.6 & 0.4 & - \\
\hline & & $95 \%$ & $79 \%$ & $0 \%$ & $8 \%$ & $0 \%$ & $13 \%$ & $5 \%$ & $0 \%$ \\
\hline \multirow[t]{3}{*}{ while } & $n$ & 25 & 14 & 19 & 10 & 8 & 22 & 8 & 3 \\
\hline & $f$ & 5.0 & 2.7 & 3.8 & 1.9 & 1.6 & 4.2 & 1.6 & 0.6 \\
\hline & & $42 \%$ & $29 \%$ & $32 \%$ & $20 \%$ & $13 \%$ & $45 \%$ & $13 \%$ & $6 \%$ \\
\hline \multirow[t]{3}{*}{ Total } & $n$ & 161 & 82 & 52 & 43 & 21 & 48 & 21 & 17 \\
\hline & $f$ & 32.4 & 15.8 & 10.5 & 8.3 & 4.2 & 9.3 & 4.2 & 3.3 \\
\hline & & $63 \%$ & $43 \%$ & $21 \%$ & $23 \%$ & $8 \%$ & $25 \%$ & $8 \%$ & $9 \%$ \\
\hline
\end{tabular}

adverbs are commonly used and decrease slightly in frequency, but paratactic conjunctions are used notably more frequently now than in 1982/83. The distribution of the data is statistically significant according to a chi-square test $\left(\chi^{2}=5.98[\mathrm{df}=2], p=0.0503\right)$.

These observations may signal a trend in preference from a mainly subordinative structure using hypotactic conjunctions or conjunctive adverbs towards a more coordinative structure increasingly relying on paratactic conjunctions. The diachronic development is visualized in Figure 1, which also shows that there

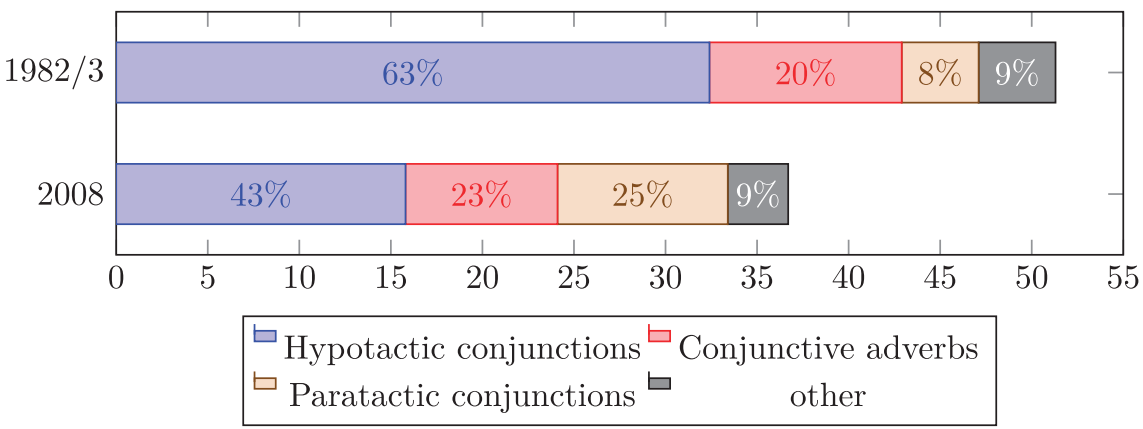

Figure 1: Diachronic change in translations of English concessive conjunctions: proportional and normalized frequencies. 
Table 5: Diachronic change in the taxis of concessive clause complexes in the parallel corpus.

\begin{tabular}{|c|c|c|c|c|c|c|}
\hline & \multicolumn{2}{|c|}{ Hypotaxis } & \multicolumn{2}{|c|}{ Parataxis } & \multicolumn{2}{|r|}{ Other } \\
\hline & $f$ & & $f$ & & $f$ & \\
\hline $1982 / 83$ & 32.4 & $65 \%$ & 14.7 & $29 \%$ & 2.8 & $6 \%$ \\
\hline 2008 & 15.8 & $45 \%$ & 17.6 & $50 \%$ & 1.9 & $5 \%$ \\
\hline Change & -16.6 & $-20 p p$ & +2.9 & $+21 p p$ & -0.9 & $-1 p p$ \\
\hline
\end{tabular}

are fewer conjunctions used overall, probably due to a decline of the four English conjunctions under analysis in the source texts.

A direct comparison between hypotactic and paratactic constructions shows that, overall, paratactic constructions are only slightly increasing in normalized frequency (Table 5). The increase in their proportion of the overall amount of constructions seems to be due to the decline of although, (even) though and while in the source texts. The decrease in the frequency with which hypotactic constructions are used to translate them, on the other hand, is notable in both normalized and proportional frequency.

The relative frequency ratios for each type of connection yield the graph in Figure 2. A line has been drawn at $y=1$ to show the border between increase and decrease in frequency (see Section 3.3). The graph confirms that hypotactic constructions are decreasing to a significant extent. Paratactic constructions are

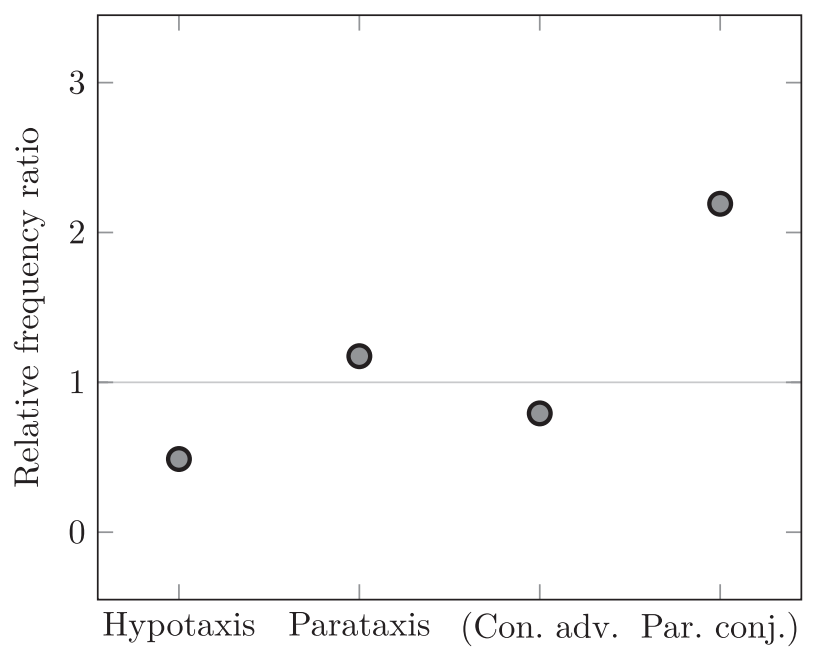

Figure 2: Hypotactic and paratactic constructions in the parallel corpus: relative frequency ratios. 
made up of conjunctive adverbs and conjunctions, which are shown individually in this figure. Conjunctive adverbs show no significant change, since the relative frequency ratio is near 1; only paratactic conjunctions are increasing significantly. The overall relative frequency ratio for paratactic constructions, however, is close to 1 , which means that, as argued above, there is no diachronic change in the actual frequency with which paratactic constructions are used. Thus, while there is a proportional change between hypotaxis and parataxis, that change is due to the decrease in frequency in hypotactic constructions, and not due to an increase in paratactic constructions.

To confirm that these findings are indeed issues of translated language and not perhaps due to changes made by editors, I have analysed translations of the four English conjunctions under analysis in the manuscript corpus. The result is that thirteen clause complexes were translated hypotactically and 62 were translated paratactically, and in each case only one instance was changed to the other taxis by the editor, suggesting a low level of editorial influence on this issue. Therefore, we can conclude that translators seem to be primarily responsible for the decline in frequency of hypotaxis.

As hypotactic conjunctions seem to decline in the parallel corpus over the analysed time span, we would also expect them to be introduced less commonly by translators into constructions where the source text does not have a hypotactic conjunction. However, that does not seem to be the case entirely, as conjunctions seem to be introduced with increasing frequency (Table 6). Examples below (3 and 4) show uses of obwohl where the presence of a conjunctive adverb (given in example [3]) or a preposition (despite in example [4]) in the source text may have made a structurally equivalent choice more likely.

Table 6: Normalized frequency of concessive conjunctions introduced by the translators.

\begin{tabular}{lrr}
\hline & $\mathbf{1 9 8 2 / 8 3}$ & $\mathbf{2 0 0 8}$ \\
\hline obwohl & 1.8 & 4.0 \\
auch wenn & 1.8 & 3.1 \\
doch & 0.8 & 4.0 \\
\hline
\end{tabular}

(3) Why were these attempts to automate the nonstore purchasing of groceries so short-lived, especially given favorable demographic and lifestyle trends? (HBR 4/81,75)

Warum waren diese Versuche, den Nonstore-Einkauf von Lebensmitteln zu automatisieren, so kurzlebig, obwohl die Trends hinsichtlich Bevölkerungsstruktur und Lebensstils günstig waren? (HBM 4/82,14) 
(4) However, the councilmen desired to continue the new budget system despite a lack of significant cost savings or cost reallocations. (HBR 6/77,76) Die Stadträte wünschten aber, am neuen Budgetierungssystem festzuhalten, obwohl es zu keiner signifikanten Einsparung oder Neuverteilung von Mitteln gekommen war. (HBM 1/83,13)

The main findings from the parallel corpus, then, are that there is a strong decline in hypotactic structures but no notable increase in frequency in paratactic structures. The latter have increased their proportion of translation choices for concessive constructions as a result of a decline in the use of conjunctions in the source texts in this genre.

While hypotactic conjunctions seem to be used less to translate source text equivalents, they appear to be introduced more often in cases where the source text has no conjunction. That may or may not be exclusive to concessive conjunctions, and may also confirm the view that German still tends to mark logical relations explicitly in translation (Stein 1979; Hansen Schirra et al. 2007).

\subsection{Analysis of the comparable corpus}

The comparable corpus exhibits a diachronic increase in normalized frequency of each construction type (Table 7), which is highly statistically significant $\left(x^{2}=13.6[\mathrm{df}=2], p=0.0011\right)$. This increase is especially strong for paratactic conjunctions. According to the proportional frequency data, hypotactic conjunctions show no diachronic shift in usage frequency. Paratactic conjunctions are used proportionally more often, and conjunctive adverbs are used proportionally less often. As is the case in the parallel corpus, then, conjunctive adverbs behave notably different from paratactic conjunctions within the group of paratactic structures.

Table 7: Concessive syntactic function types in the comparable corpus.

\begin{tabular}{|c|c|c|c|c|c|c|}
\hline & \multicolumn{2}{|c|}{$\begin{array}{l}\text { Hypotactic } \\
\text { conjunction }\end{array}$} & \multicolumn{2}{|c|}{$\begin{array}{r}\text { Conjunctive } \\
\text { adverb }\end{array}$} & \multicolumn{2}{|r|}{$\begin{array}{l}\text { Paratactic } \\
\text { conjunction }\end{array}$} \\
\hline & $f$ & & $f$ & & $f$ & \\
\hline $1982 / 83$ & 35.0 & $14 \%$ & 195.6 & $76 \%$ & 28.8 & $10 \%$ \\
\hline 2008 & 52.1 & $15 \%$ & 221.9 & $63 \%$ & 77.0 & $22 \%$ \\
\hline Change & +17.1 & $+1 p p$ & +26.3 & $-13 p p$ & +48.2 & $+12 p p$ \\
\hline
\end{tabular}


This may suggest that while the English source texts (and by extension, their German translations) rely progressively less on conjunctions to express concession, the use of concessive conjunctions in German is actually increasing, which is observed in non-translations and, as speculated above, in the rising number of conjunctions introduced into the translated texts.

The observations in this section are comprehensively displayed in Figure 3. While hypotaxis is decreasing in frequency in the parallel corpus, it seems to increase as part of a general increase in connectives in the comparable corpus. Paratactic conjunctions and conjunctive adverbs, on the other hand, behave remarkably similarly in the two corpora; the former increase strongly in both translations and non-translations while the latter show no significant change.

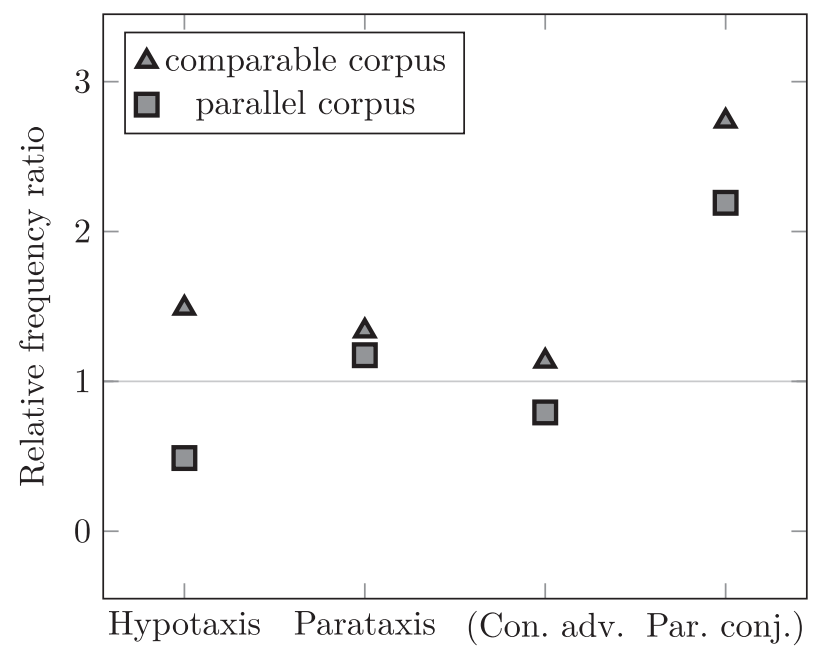

Figure 3: Hypotactic and paratactic constructions in both corpora: relative frequency ratios.

In all, the comparable corpus does not entirely corroborate the findings from the parallel corpus. Based on the parallel corpus analysis, we would have expected a decrease in hypotactic structures, which is not the case. Instead, hypotactic structures remain stable or even increase in frequency somewhat between the two periods of analysis. Therefore, it seems as though the decrease of hypotactic constructions in the parallel corpus is not a phenomenon that happens generally in this genre, but is limited to translated language.

In addition, given the notable decrease in concessive conjunctions in translated texts (which must be traced to the source texts), it is striking that there is an increase in concessive conjunctions in non-translated texts. This may show 
that conjunctions are strengthening their positions as the prime way of achieving cohesion when expressing concessive meaning relations.

\section{Sentence-initial concessive conjunctions}

\subsection{Analysis of the parallel corpus}

The sentence-initial concessive conjunction but, which is used with a similar frequency in 1982/83 and 2008, has been translated in various ways as shown in Table 8. Among them, sentence-initial doch shows the strongest increase in frequency $(+13.5)$, while the frequencies of sentence-initial aber and of conjunctive adverbs as translation equivalents have decreased highly statistically significantly $\left(\chi^{2}=11.89[\mathrm{df}=2], p=0.0026\right)$. Thus, doch is now used as commonly as aber and conjunctive adverbs to translate sentence-initial but.

Table 8: Translations of sentence-initial But into German.

\begin{tabular}{|c|c|c|c|c|c|c|}
\hline & \multicolumn{2}{|c|}{$1982 / 83$} & \multicolumn{2}{|r|}{2008} & \multicolumn{2}{|r|}{ Change } \\
\hline & $f$ & & $f$ & & $f$ & \\
\hline aber & 30.0 & $48 \%$ & 21.8 & $38 \%$ & -8.2 & $-10 p p$ \\
\hline doch & 5.2 & $8 \%$ & 18.7 & $33 \%$ & +13.5 & $+25 p p$ \\
\hline Conj. adv. & 20.9 & $34 \%$ & 11.6 & $20 \%$ & -9.3 & $-14 p p$ \\
\hline omitted & 4.8 & $8 \%$ & 3.7 & $6 \%$ & -1.2 & $-2 p p$ \\
\hline other & 1.0 & $2 \%$ & 1.7 & $3 \%$ & +0.7 & $+1 p p$ \\
\hline Total & 61.9 & $100 \%$ & 57.4 & $100 \%$ & -4.5 & \\
\hline
\end{tabular}

Though the conjunction aber decreases in frequency, the overall picture that emerges is that sentence-initial conjunctions are becoming more popular than conjunctive adverbs in the translation of but. Together, they have increased by 15 percentage points, almost the same amount that conjunctive adverbs have lost (Table 8), which may signal an adoption of the source language pattern.

To assess the role of editors in this process, the manuscript corpus has been analysed in the same way as the parallel corpus. On the whole, editors do not seem to object to the sentence-initial use of aber. They did intervene in $15 \%$ of cases, and I will take a closer look at those cases here. Their actions (Table 9) mostly seem to affect conjunctive adverbs, especially jedoch, which editors swap for another adverb, conjunction or which they omit entirely. 
Table 9: Editorial changes to translations of sentence-initial But.

\begin{tabular}{llllr}
\hline Editorial action & & & & 119 instances \\
\hline No change & & & & 101 \\
& Conj. & $\rightarrow$ & Conj. adv. & 2 \\
& Conj. & $\rightarrow$ & omitted & 1 \\
& Conj. adv. & $\rightarrow$ & Conj. & 1 \\
Change & Conj. adv. & $\rightarrow$ & omitted & 4 \\
& Conj. adv. & $\rightarrow$ & other & 1 \\
& jedoch & $\rightarrow$ & other Conj. adv. & 6 \\
& omitted & $\rightarrow$ & Conj. & 1 \\
& omitted & $\rightarrow$ & Conj. adv. & 1 \\
& other & $\rightarrow$ & Conj. & 1 \\
\hline
\end{tabular}

While the data are admittedly too small to provide any significant insights, the editors' concentration on conjunctive adverbs, especially jedoch ('however'), matches the observation that conjunctive adverbs decrease in the translated texts. Example (5) shows how the conjunctive adverb jedoch in the translated manuscript (5a) was replaced by sentence-initial aber in the published version (5b). Thus, there is evidence that the use of sentence-initial aber is not just driven by translators, but also to some extent by editors, perhaps supporting the view that sentence-initial conjunctions are becoming an increasingly acceptable alternative to conjunctive adverbs.

(5) But it's not just the physical attributes of a space that influence informal interactions; "proximity," as we use the term, depends on traffic patterns [...]. (HBR 7/11,102)

a. Beim Aspekt der Nähe und dessen Einfluss auf informelle Kontakte geht es jedoch nicht nur um den physischen Abstand, sondern auch um Aufenthaltsmuster [...]. (manuscript25)

b. Aber nicht nur die physischen Eigenschaften eines Raums beeinflussen die Häufigkeit zufälliger Begegnungen. Nähe, wie wir den Begriff verstehen, hängt von den Bewegungsmustern der Mitarbeiter ab [...]. (HBM 10/11,46)

\subsection{Analysis of the comparable corpus}

In analogy to the development in the parallel corpus, the comparable corpus also exhibits a statistically highly significant $\left(\chi^{2}=8.63[\mathrm{df}=1], p=0.0033\right)$ increase of sentence-initial concessive conjunctions, especially doch (Table 10). The frequencies of aber and doch in sentence-initial use in the 1982/83 parallel 
Table 10: Frequencies of sentence-initial aber and doch in the comparable corpus.

\begin{tabular}{|c|c|c|c|c|c|}
\hline & \multicolumn{2}{|c|}{$1982 / 83$} & \multicolumn{2}{|r|}{2008} & \multirow{2}{*}{$\frac{\text { Change }}{f}$} \\
\hline & $n$ & $f$ & $n$ & $f$ & \\
\hline aber & 24 & 16.5 & 45 & 60.0 & +43.5 \\
\hline doch & 5 & 3.4 & 63 & 71.3 & +67.9 \\
\hline Total & 29 & 19.9 & 108 & 122.3 & +102.4 \\
\hline
\end{tabular}

corpus (see Table 8), which only include the translations of sentence-initial but, are higher than those in the 1982/83 comparable corpus. This suggests that the use of sentence-initial concessive conjunctions was popular in translations before it became frequent in non-translated language as well, which is a possible indicator for this shift being motivated by language contact in translation, or at least contact with English language material.

Overall, then, it seems that there is a tendency in German towards an increasing use of sentence-initial conjunctions, especially doch, at the expense of the conventional way of marking concession, such as conjunctive adverbs. That development can be observed in both translated and non-translated text.

\section{Discussion}

This diachronic study of taxis in concessive clauses in German business articles from 1982/83 and 2008 has shown that hypotactic structures are used with decreasing frequency in that time period in translated language. In that respect, the genre seems to have undergone a similar change to that found in popular science by Becher (2011: 195-197). It also ties in with my observations on causal clauses in the business genre, where there is also a decrease in hypotactic constructions (Bisiada 2013: 22), though hypotaxis is used more often to express causal relationships than concessive relationships.

In non-translated language, however, there is no sign of such a decrease, as the frequency of hypotactic constructions in 2008 is significantly higher in the comparable corpus (52.1) than in the parallel corpus (15.8), while they were almost the same in 1982/83 (32.4 in the parallel corpus and 35 in the comparable corpus). Even in translated language, and despite the decrease in frequency they seem to undergo, there is evidence to suggest that hypotactic conjunctions remain a common way of combining clauses in this genre as translators 
introduce hypotactic conjunctions into their texts with increasing frequency. As they are still used in two out of five cases, hypotactic constructions do not seem to be a marginal phenomenon in business writing, as they seem to be in popular science (Becher 2011: 197).

At the same time, there is no significant increase in paratactic structures on the whole, as only paratactic conjunctions are increasing. The decrease in hypotaxis may be explained by the phenomenon of sentence splitting (see Bisiada 2014). When sentences with a concessive logical relation are split, a sentence-initial conjunction is the only feasible way to maintain the connection, and sentence-initial concessive conjunctions tend to be paratactic aber or doch. Thus, the decrease in hypotaxis does not mean that hypotaxis is unpopular (hence its introduction elsewhere), but that sentence splitting takes precedence over concerns with logical connectivity.

An explanation for the discrepancy between the two genres, which are similar in that they unite journalistic and scientific discourse features, may be found in the fact that the overall use of conjunctions in the source texts has decreased. This phenomenon, i. e. English language users in the business genre seem to use fewer conjunctions to achieve text cohesion, may have prevented the notable increase in parataxis that was observed in popular science texts. More research is necessary to confirm this rather speculative explanation.

Similarities between the genres exist in the use of sentence-initial concessive conjunctions, which has been found to be increasing in business writing as in popular science. Becher et al. (2009: 146-147) see the increasing frequency of sentence-initial conjunctions in German popular science texts as an "adoption of Anglophone communicative norms" through contact with prestigious English source texts in translation. In business writing, the increasing use of sentenceinitial conjunctions may have been driven by their frequent occurrence in translations, both as source text equivalents and where they were introduced by translators. The data show an increase in the use of the conjunction doch even where the source text clause complex does not have an overt concessive relationship.

By adopting a method of diachronic corpus investigation of translations and non-translations in popular science texts, this paper has aimed to replicate the findings in the business genre. It has found that German language users do not increasingly prefer paratactic over hypotactic constructions. Though the use of hypotaxis in concessive constructions has decreased more strongly than in causal constructions (Bisiada 2013), it continues to be used frequently.

What could be replicated is the finding that concessive conjunctions are increasingly used in sentence-initial position, mirroring current conventions in English. As the latter development has been shown to have happened first in 
translations and then in non-translations, existing claims that this change has been affected by translation can be supported. While the influence of language contact in translation on language change is hard to prove, the findings discussed in this paper, at least as far as sentence-initial conjunctions are concerned, lend more support to the method of discovering such change through diachronic corpus studies.

\section{References}

Barth-Weingarten, Dagmar \& Elizabeth Couper-Kuhlen. 2002. On the development of final though: A case of grammaticalization? In Ilse Wischer \& Gabriele Diewald (eds.), New reflections on grammaticalization, 345-362. Amsterdam: John Benjamins.

Baumgarten, Nicole. 2007. Converging conventions? Macrosyntactic conjunction with English and and German und. Text \& Talk 27(2). 139-170.

Baumgarten, Nicole. 2008. Writer construction in English and German popularized academic discourse: The uses of we and wir. Multilingua 27(4). 409-438.

Baumgarten, Nicole \& Demet Özçetin. 2008. Linguistic variation through language contact in translation. In Peter Siemund \& Noemi Kintana (eds.), Language contact and contact languages, 293-316. Amsterdam: John Benjamins.

Becher, Viktor. 2011. Von der Hypotaxe zur Parataxe: Ein Wandel im Ausdruck von Konzessivität in neueren populärwissenschaftlichen Texten. In Eva Breindl, Gisella Ferraresi \& Anna Volodina (eds.), Satzverknüpfungen. Zur Interaktion von Form, Bedeutung und Diskursfunktion, 181-209. Berlin: de Gruyter.

Becher, Viktor, Juliane House \& Svenja Kranich. 2009. Convergence and divergence of communicative norms through language contact in translation. In Kurt Braunmüller \& Juliane House (eds.), Convergence and divergence in language contact, 125-152. Amsterdam: John Benjamins.

Bennett, Karen. 2011. The scientific revolution and its repercussions on the translation of technical discourse. The Translator 17(2). 189-210.

Bennett, Karen. 2013. English as a lingua franca in academia: Combating epistemicide through translator training. The Interpreter and Translator Trainer 7(2). 169-93.

Bisiada, Mario. 2013. Changing conventions in German causal clause complexes: A diachronic corpus study of translated and non-translated business articles. Languages in Contrast 13(1). 1-27.

Bisiada, Mario. 2014. “Lösen Sie Schachtelsätze möglichst auf”: The impact of editorial guidelines on sentence splitting in German business article translations. Applied Linguistics Advance Online Access.

Damerau, Fred J. 1993. Generating and evaluating domain-oriented multi-word terms from texts. Information Processing \& Management 29(4). 433-447.

Edmundson, Harold P. \& Ronald E. Wyllys. 1961. Automatic abstracting and indexing-survey and recommendations. Communications of the ACM 4(5). 226-234.

Fischer, Klaus. 2007. Komplexität und semantische Transparenz im Deutschen und Englischen. Sprachwissenschaft 32(4). 355-405. 
Fischer, Klaus. 2013. Satzstrukturen im Deutschen und Englischen: Typologie und Textrealisierung. Berlin: Akademie Verlag.

Fitzgerald, Jason C. 2014. An analysis of causal asyndetic constructions in United States history textbooks. Functional Linguistics 1(5). 1-17.

Hansen-Schirra, Silvia. 2011. Between normalization and shining-through: Specific properties of English-German translations and their influence on the target language. In Svenja Kranich, Viktor Becher, Steffen Höder \& Juliane House (eds.), Multilingual discourse production: Diachronic and synchronic perspectives, 135-162. Amsterdam: John Benjamins.

Hansen-Schirra, Silvia, Stella Neumann \& Erich Steiner. 2007. Cohesive explicitness and explicitation in an English-German translation corpus. Languages in Contrast 7(2). 241-265.

Hentschel, Elke. 2010. Deutsche Grammatik. Berlin: de Gruyter.

House, Juliane. 2006. Communicative styles in English and German. European Journal of English Studies 10(3). 249-267.

House, Juliane. 2011a. Linking constructions in English and German translated and original texts. In Svenja Kranich, Viktor Becher, Steffen Höder \& Juliane House (eds.), Multilingual discourse production: Diachronic and synchronic perspectives, 163-182. Amsterdam: John Benjamins.

House, Juliane. 2011b. Using translation and parallel text corpora to investigate the influence of global English on textual norms in other languages. In Alet Kruger, Kim Wallmach \& Jeremy Munday (eds.), Corpus-based translation studies, 187-208. London: Continuum.

Koller, Werner. 1998. Übersetzungen ins Deutsche und ihre Bedeutung für die deutsche Sprachgeschichte. In Werner Besch, Anne Betten, Oskar Reichmann \& Stefan Sonderegger (eds.), Ein Handbuch zur Geschichte der deutschen Sprache und ihrer Erforschung, 210-229. Berlin: de Gruyter.

König, Ekkehard, Detlef Stark \& Susanne Requardt. 1990. Adverbien und Partikeln: Ein deutsch-englisches Wörterbuch. Heidelberg: Groos.

Kranich, Svenja. 2011. To hedge or not to hedge: The use of epistemic modal expressions in popular science in English texts, English-German translations and German original texts. Text and Talk 31(1). 77-99.

Kranich, Svenja. 2014. Translation as a locus of language contact. In Juliane House (ed.), Translation: A multidisciplinary approach, 96-115. Basingstoke: Palgrave Macmillan.

Kranich, Svenja, Viktor Becher \& Steffen Höder. 2011. A tentative typology of translationinduced language change. In Svenja Kranich, Viktor Becher, Steffen Höder \& Juliane House (eds.), Multilingual discourse production, 11-44. Amsterdam: John Benjamins.

Kranich, Svenja, Juliane House \& Viktor Becher. 2012. Changing conventions in English-German translations of popular scientific texts. In Kurt Braunmüller \& Christoph Gabriel (eds.), Multilingual individuals and multilingual societies, 315-334. Amsterdam: John Benjamins.

Malamatidou, Sofia. 2013. Passive voice and the language of translation: A comparable corpusbased study of modern Greek popular science articles. Meta 58(2). 411-429.

Manning, Christopher D. \& Hinrich Schütze. 1999. Foundations of statistical natural language processing. Cambridge, Mass.: MIT Press.

Mossop, Brian. 2014. Revising and editing for translators. 3rd edn. Abingdon: Routledge.

Muñoz Martín, Ricardo. 2010. On paradigms and cognitive translatology. In Gregory M. Shreve \& Erik Angelone (eds.), Translation and cognition, 169-187. Amsterdam: John Benjamins. 
Musacchio, Maria Teresa. 2005. The influence of English on Italian: The case of translations of economics articles. In Gunilla Anderman \& Margaret Rogers (eds.), In and out of English: For better, for worse? 71-96. Clevedon: Multilingual Matters.

Musacchio, Maria Teresa \& Giuseppe Palumbo. 2010. Following norms, taking risks: A study of the use of connectives in a corpus of translated economics articles in Italian. In Carmen Heine \& Jan Engberg (eds.), Reconceptualizing LSP: Online proceedings of the XVII European LSP symposium 2009, 1-11. Aarhus: Aarhus Universitet.

Neumann, Stella. 2011. Assessing the impact of translations on English-German language contact. In Svenja Kranich, Viktor Becher, Steffen Höder \& Juliane House (eds.), Multilingual discourse production: Diachronic and synchronic perspectives, 233-256. Amsterdam: John Benjamins.

Stein, Dieter. 1979. Zur Satzkonnektion im Englischen und Deutschen: Ein Beitrag zu einer kontrastiven Vertextungslinguistik. Folia Linguistica 13. 303-319.

\section{Bionote}

\section{Mario Bisiada}

Mario Bisiada received his PhD in Intercultural and Translation Studies from the University of Manchester. He is currently lecturer at the Universitat Pompeu Fabra, where he is a member of the Grup d'Estudis del Discurs. His research focusses on the corpus-based study of translated discourse, and he has published on language contact in translation in causal clauses and sentence splitting. He is currently working on a monograph on the effects of editing on translated language. 